\title{
Oil squeezing power losses in gears: a CFD analysis
}

\author{
F. Concli \& C. Gorla \\ Politecnico di Milano, Department of Mechanical Engineering, Milano, \\ Italy
}

\begin{abstract}
Efficiency is becoming more and more of a main concern in the design of power transmissions and the demand for high efficiency gearboxes is continuously increasing; also the euro standards for the reduction of pollutant emissions from light vehicles imposed to improve the efficiency of the engines and gear transmissions are becoming more and more restrictive. For this reason the resources dedicated to this goal are continuously increasing.

The first step to improve efficiency is to have appropriate models to compare different design solutions. Even if the efficiency of transmissions is quite high compared to the efficiency of the engines and appropriate models to predict the power losses due to gear meshing, to bearings and to seals that already exist, in order to have further improvement, some aspects like the power losses related to the oil churning, oil squeezing and windage are still to be investigated. In previous papers, the authors have investigated by means of CFD (computational fluid dynamic) analysis and experimental measurements the churning losses of planetary speed reducers (in which there is a relative motion between the "planets + planet carrier" and the lubricant). This report is focused on the oil squeezing power loss. This kind of loss is associated with the compressionexpansion process by the meshing teeth. The contraction of the volume at the gear mesh implies an overpressure that induces a fluid flow primarily in the axial direction and this, for viscous fluids, means additional power losses and a decrease of efficiency.

In this work this phenomenon has been studied by means of some CFD simulations. The influence of some operating conditions, such as the lubricant properties, rotational speed and temperature, have been studied.

Keywords: efficiency, gear, power losses, oil squeezing, lubrication, CFD.
\end{abstract}




\section{Introduction}

As the fuel economy requirements and euro standards for the reduction of pollutant emissions are becoming more and more stringent, efficiency is becoming a main concern also in the design of power transmissions. Reducing fuel consumption and particulate emission levels through increasing efficiency has not only a strong impact on the economy and on the environment, but also on the reliability on the transmissions: a reduction of the power losses means also a reduction of the heat generated and, therefore, of the operating temperature of the transmission. A lower temperature is favorable for the system reliability.

Sources of losses in a gearbox can be classified according to [1] into two main categories: (i) load dependent power losses and (ii) load independent power losses. The load dependent power losses are primarily related to a mechanical power loss due to friction at the gear contact and between the rolling elements and the races of the bearings. The load independent power losses, in turn, are primarily related to viscous effects. These losses can be further subdivided into oil churning and windage losses that are the result of the interaction between the oil/air and the moving/rotating elements like gears and shafts, into pocketing/squeezing losses due to the pumping effect of the mating gears and into other viscous dissipations like those of the bearings.

In order to predict these kinds of losses, literature provides many publications about the load dependent power losses, but only few works about load independent power losses. These works are primarily concerning the churning losses of ordinary gears, the spin power losses and the losses of the bearings. What is still wanted are appropriate studies to predict the oil pumping/squeezing power losses. The works on this topic are few and simplified. Strasser [10] proposed a simplified fluid-dynamic model to predict the oil squeezing power losses in a spur gear pair. This model takes into account the variation of the gap between the teeth but it approximates the geometry. Seetharaman and Kahraman [11] proposed a physic based fluid mechanics model to predict the spin power losses of a gear pair due to oil churning and windage. This model calculate the losses like the sum of the losses associated to the interactions of individual gears and the fluid and the power losses due to pumping of the oil at the gear mesh. To predict the oil pumping losses, Seetharaman and Kahraman developed an analytical model that take into account the variation of the volume of the gap between the teeth without simplifying the geometry like in the model proposed by Strasser. These models are able to give results in a very short time but they give only approximate results. For this reason the authors have investigated this kind of losses by mean of CFD simulations that are able to correctly solve the velocity and the pressure fields without simplifications and, therefore, give more information about the phenomena. In this study the influence on this kind of losses of the oil temperature and of the rotational speed of the gears have been investigated. 


\section{Problem description}

Between two mating gears, the volume of the cavity between the teeth is continuously changing. The sudden contraction of this volume caused by the gears revolution implies an overpressure in the gap. The lubricant is therefore squeezed out primary in the axial directions. After the reaching of the minimum value for the volume, this increase again causing a negative pressure in the gap and, consequently, a fluid flow takes place from the oil bath to the cavity between the teeth.

This process is cyclic and, in general, there are multiple cavities that are squeezed together. Due to the viscous properties of the lubricant, this phenomenon induces power losses.

Figure 1 illustrates the phenomena: the volume (marked in grey) decreases from picture 1a (where a gear pair starts the contact) to picture 1b. Figure 1c shows the moment in which a second gear pair mates and figure 1d the quick growth of the cavity volume.
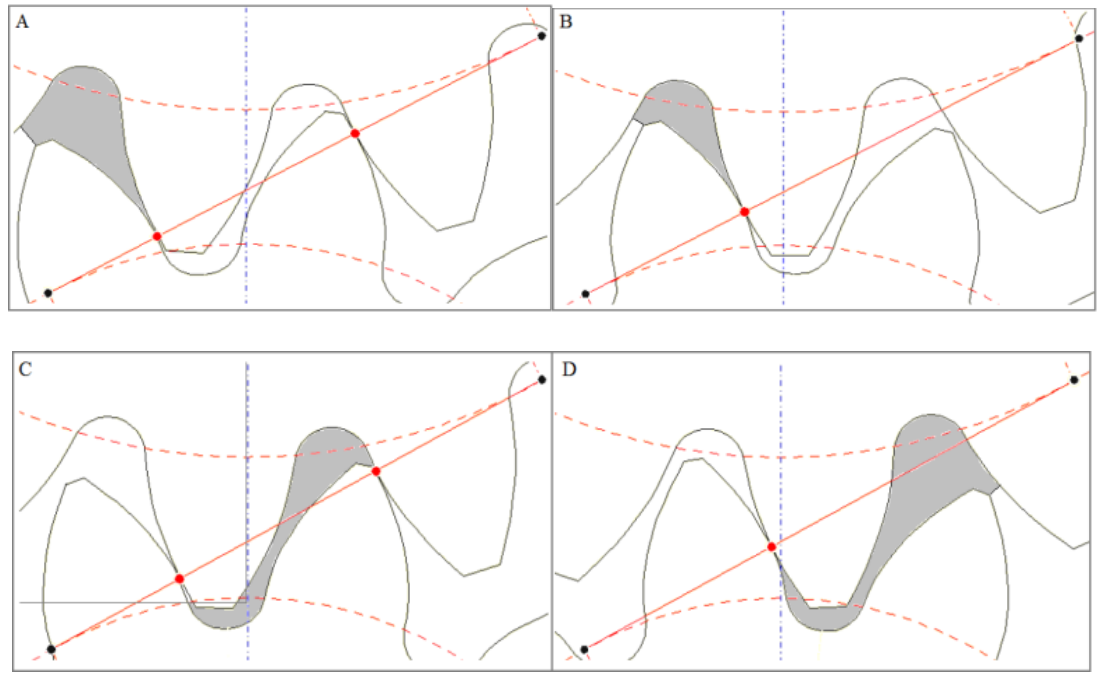

Figure 1: Change of the volume of the cavity during the engaging of the gears.

\section{Geometry}

In order to study this kind of power losses, a spur gear pair has been used. Pinion and gear have the same dimensions. Table 1 summarized the main parameter of the gears.

For this initial study, a full immersion lubrication has been adopted. This solution has been chosen in order to simplify the model. A partial immersion, in fact, complicates a lot the problem because it involves multiphase flows. The 
aim of this initial study was to understand the effect of the mating gears on the axial flows, so the full immersion lubrication was considered appropriate at this point of the research.

Table 1: Geometrical parameters of the gear pair.

\begin{tabular}{|c|c|}
\hline $\begin{array}{c}\text { helix angle on } \\
\text { reference } \\
\text { cylinder } \beta \mathrm{b} \text { [rad] }\end{array}$ & 0 \\
\hline Pressure angle $\alpha^{\prime}[\mathrm{rad}]$ & 0,358452 \\
\hline $\begin{array}{c}\text { Working pressure } \\
\text { angle } \alpha \text { [rad] }\end{array}$ & 0,349066 \\
\hline $\begin{array}{c}\text { Centre distance a } \\
{[\mathrm{mm}]}\end{array}$ & 28,8 \\
\hline $\begin{array}{c}\text { Working centre } \\
\text { distance } \mathrm{a}^{\prime}[\mathrm{mm}]\end{array}$ & 28,9 \\
\hline Tip radius ra [mm] & 15,175 \\
\hline Root circle ri [mm] & 13,4375 \\
\hline
\end{tabular}

\begin{tabular}{|c|c|}
\hline $\begin{array}{c}\text { Pitch circle r } \\
\text { [mm] }\end{array}$ & 14,4 \\
\hline $\begin{array}{c}\text { Working pitch } \\
\text { circle r' [mm] }\end{array}$ & 14,45 \\
\hline $\begin{array}{c}\text { Number of teeth z } \\
\text { Base circle rb } \\
\text { [mm] }\end{array}$ & 13,5315 \\
\hline Module m [mm] & 0,8 \\
\hline $\begin{array}{c}\text { Face width b } \\
\text { [mm] }\end{array}$ & 15,5 \\
\hline
\end{tabular}

\section{Geometrical model}

In order to reduce the number of cells and thank to the symmetry of the gear pair, only half domain has been modeled. The aim of this work was to study in detail the behavior of the lubricant in the region of meshing. For this reason only five teeth pro gear have been modeled.

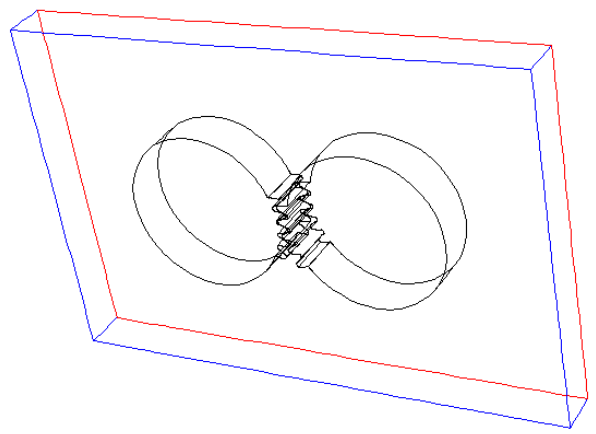

Figure 2: $\quad$ Geometrical model: marked in blue the symmetry plane.

The computational domain for the CFD analysis has been modeled by means of $3 \mathrm{D}$ cad software and discretized with a swept mesh. This meshing technique 
consists in creating a mesh on one side of the region, known as the source side, and then copying the nodes of that mesh, one element layer at a time, until the end side, known as the target side, is reached.

The whole model has been discretized with triangular prisms. This kind of elements allows a larger aspect ratio compared with the tetrahedral cells in which it will invariably affects the skewness of the cell, which is undesirable as it may affect accuracy and convergence. Some mesh refinements have been performed in order to find the best compromise between the accuracy of the solution and the computational time. The real problem during the meshing operation is that it's necessary to model the thin oil film that rise between the mating teeth. The thickness of this film has a big influence on the results in terms of power losses. For this reason some geometries with different film thickness have been modelled.

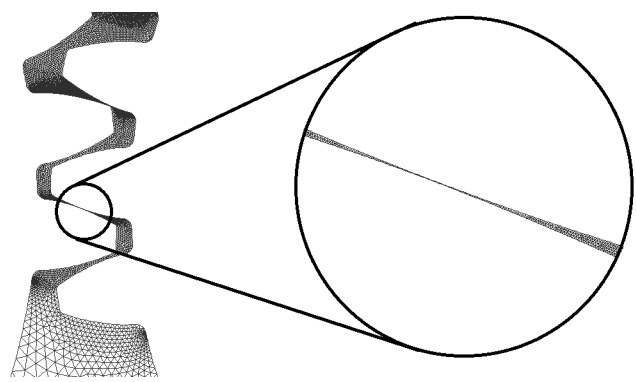

Figure 3: Details of the mesh.

After a convergence study, the final model had a film thickness of about 0.5 $\mu \mathrm{m}$. That means that the required mesh is extra fine. The smallest element has a length of about $0.2 \mu \mathrm{m}$.

Table 2: $\quad$ Mesh statistics.

\begin{tabular}{|c|c|}
\hline minimum volume $\left[\mathrm{m}^{3}\right]$ & $3.01 \mathrm{E}-09$ \\
\hline maximum volume $\left[\mathrm{m}^{3}\right]$ & $5.51 \mathrm{E}-03$ \\
\hline total volume $\left[\mathrm{m}^{3}\right]$ & $3.14 \mathrm{E}+01$ \\
\hline minimum face area $\left[\mathrm{m}^{2}\right]$ & $1.60 \mathrm{E}-06$ \\
\hline maximum face area $\left[\mathrm{m}^{2}\right]$ & $6.03 \mathrm{E}+00$ \\
\hline minimum orthogonal quality & 0.38633 \\
\hline
\end{tabular}

\section{Numerical model}

To simulate the problem, a VOF approach has been used. This method is an Eulerian method characterized by a mesh that is (in this case) moving in a certain prescribed manner to accommodate the evolving shape of the interface. 
The governing equations are the conservation equations for mass and momentum. The energy equation is not activated in these simulations.

$$
\begin{gathered}
\frac{\partial \rho}{\partial t}+\nabla \cdot(\rho \overrightarrow{\boldsymbol{v}})= \\
\frac{\partial}{\partial \boldsymbol{t}}(\boldsymbol{\rho} \overrightarrow{\boldsymbol{v}})+\nabla \cdot(\boldsymbol{\rho} \overrightarrow{\boldsymbol{v}})=-\nabla \boldsymbol{p}+\nabla \cdot\left[\boldsymbol{\mu}\left(\boldsymbol{\nabla} \overrightarrow{\boldsymbol{v}}+\nabla^{T}\right)\right]+\boldsymbol{\rho} \overrightarrow{\boldsymbol{g}}+\overrightarrow{\boldsymbol{F}}
\end{gathered}
$$

$\rho$ is the density, $t$ is the time, $\overrightarrow{\boldsymbol{v}}$ is the velocity vector, $P$ is the pressure, $\rho \overrightarrow{\boldsymbol{g}}$ and $\overrightarrow{\boldsymbol{F}}$ are the gravitational body force and external body forces.

For compressible flows, the unknowns are the velocity components and the density while the pressure is evaluated with a constitutive equation. For incompressible flows, the variables are the pressure and the velocity components. The solution of the system of equations for incompressible flows is accomplished by the fact that there are not equations where the pressure is explicity defined. To calcluate it, the continuity equation is substituted with an equation for the pressure; with some manipulation the pressure appears like unknown term in the momentum equation.

For this reasons a SIMPLE (Semi Implicit Method for Pressure-Linked Equations) scheme has been adopted as suggested for flows in closed domains to solve the pressure-velocity-couplig. This algorithm uses a relationship between velocity and pressure corrections to enforce mass conservation and to obtain the pressure field. The idea is that the pressure field must guarantee, at every time, the continuity equations. Is it therefore necessary to obtain a diefferntial equation for the pressure unknown derived from continuity and momentum equations.

In this method the pressure field is calculated as

$$
P^{n+1}=P^{*}+P^{\prime}
$$

where $P^{*}$ is the estimated pressure guessed or obtained at the previous time step/iteration from the momentum equations and $P^{\prime}$ is the pressure correction

The velocity field is calculated as

$$
\overrightarrow{\boldsymbol{v}}^{n+1}=\overrightarrow{\boldsymbol{v}}^{*}+\overrightarrow{\boldsymbol{v}}
$$

where $\overrightarrow{\boldsymbol{v}}^{*}$ is the estimated velocity calculated from the pressure $P^{*}$ and $\overrightarrow{\boldsymbol{v}}^{\prime}$ is the velocity correction.

The gear surfaces have been set like no slip walls and the lateral sides of the domain as zero pressure to simulate the steady oil bath and as symmetry respectively.

In order to reproduce the operating conditions, a rigid motion of the boundaries corresponding to the pinion and the gear has been applied by means of User Defined Functions (UDF) written in the c++ language. With this boundary motion it is possible to reproduce the real operating conditions in which gears are mating together. The time step for the transient analysis has been 
chosen as dynamic. This means that every step, the new time increment depends on the velocity field.

$$
t=\frac{V_{\text {cell,min }}^{\frac{1}{3}}}{U}
$$

where $V_{\text {cell,min }}$ is the volume of the smallest cell in the computational domain and $U$ is the velocity scale of the problem. This allows us to increase the calculations without the risk to lose the convergence.

This boundary motion implies a deformation of the fluid domain. For this reason it is necessary do update the mesh every time step. In order to do that, a dynamic mesh model has been adopted: the spring-based smoothing + remeshing. In this method, the edges between any two mesh nodes are idealized as a network of interconnected springs. The initial spacing of the edges before any boundary motion constitutes the equilibrium state of the mesh. A displacement at a given boundary node will generate a force proportional to the displacement along all the springs connected to the node. With a linear elastic behavior, the force on a mesh node can be written as

$$
\overrightarrow{\boldsymbol{F}}_{i}=\sum_{j}^{n_{i}} k_{i j}\left(\Delta \overrightarrow{\boldsymbol{x}}_{j}-\Delta \overrightarrow{\boldsymbol{x}}_{i}\right)
$$

where $\Delta \overrightarrow{\boldsymbol{x}}_{j}$ and $\Delta \overrightarrow{\boldsymbol{x}}_{i}$ are the displacements of node $i$ and its neighbor $j, n_{i}$ is the number of the neighboring nodes connected to the node $i$ and $k_{i j}$ is the spring constant between node $i$ and its neighbor $j$. The spring constant for the edge connecting nodes $i$ and $j$ is defined as

$$
k_{i j}=\frac{1}{\sqrt{\left|\vec{x}_{j}-\vec{x}_{i}\right|}}
$$

At equilibrium, the net force on a node due to all the springs connected to the node must be zero. This condition results in an iterative equation such that

$$
\Delta \overrightarrow{\boldsymbol{x}}_{i}^{m+1}=\frac{\sum_{j}^{n_{i}} k_{i j} \Delta \overrightarrow{\boldsymbol{x}}_{j}^{m}}{\sum_{j}^{n_{i}} k_{i j}}
$$

Since displacements are known at the boundaries, Equation (8) is solved using a Jacobi sweep on all interior nodes. At convergence, the positions are updated such that

$$
\overrightarrow{\boldsymbol{x}}_{i}^{n+1}=\overrightarrow{\boldsymbol{x}}_{i}^{n}+\Delta \overrightarrow{\boldsymbol{x}}_{j}^{m, \text { converged }}
$$

where $n+1$ and $n$ re used to denote the positions at the next time step and the current time step, respectively.

Figure 4 shows the adopted mesh before and after the calculations. It is possible to appreciate the good efficiency of the smoothing-based algorithm for the mesh update. After the iterations, the elements have still a good aspect ratio and approximately the same dimensions that they had at the beginning. 

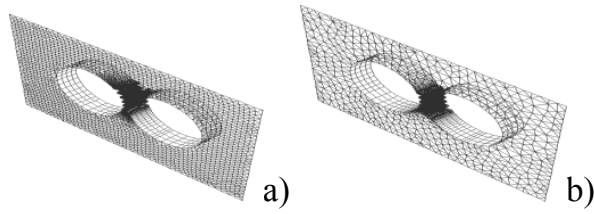

Figure 4: a) Detail of the mesh at the first time step; b) Detail of the mesh after some iterations.

\section{Operating conditions}

The purpose of the simulations is to calculate the power losses due to oil squeezing under different operating conditions.

In order to do that, the resistant torque on the driving shaft has been monitored. This resistant torque is calculated with a surface integral on the moving walls with respect to the gearbox axis and it is composed of two parts: the first given by the pressure and the second by the viscous effects. Starting from the resistant torque it is possible to calculate the power losses just by multiplying it by the rotational speed. The simulations have been computed with different combinations of operating temperature (which means different density and viscosity) and rotational speed.

Table 3 shows the combinations of parameters for each simulation. $\boldsymbol{T}$ is the operating temperature in ${ }^{\circ} \mathrm{C}, \boldsymbol{\omega}$ the rotational speed of the planet carrier in $[\mathrm{rad} / \mathrm{s}], \boldsymbol{\rho}$ the density in $\left[\mathrm{Kg} / \mathrm{m}^{3}\right]$ and $\boldsymbol{\eta}$ the dynamic viscosity in [ $\left.\mathrm{Pa}^{*} \mathrm{~s}\right]$.

Table 3: $\quad$ Parameters for each simulation.

\begin{tabular}{|c|c|c|c|}
\hline $\begin{array}{c}\text { Rotational speed } \\
\omega[\mathrm{rad} / \mathrm{s}]\end{array}$ & $\begin{array}{c}\text { Temperature } \\
\mathrm{T}\left[{ }^{\circ} \mathrm{C}\right]\end{array}$ & $\begin{array}{c}\text { Density } \\
\rho\left[\mathrm{kg} / \mathrm{m}^{3}\right]\end{array}$ & $\begin{array}{c}\text { Dynamic Viscosity } \eta \\
{[\mathrm{Pa} \text { * }]}\end{array}$ \\
\hline 52 & 40 & 1040.86 & 0.2289 \\
\hline 105 & 40 & 1040.86 & 0.2289 \\
\hline 157 & 40 & 1040.86 & 0.2289 \\
\hline 52 & 65 & 1021.61 & 0.1481 \\
\hline 105 & 65 & 1021.61 & 0.1481 \\
\hline 157 & 65 & 1021.61 & 0.1481 \\
\hline 52 & 90 & 1002.36 & 0.0702 \\
\hline 105 & 90 & 1002.36 & 0.0702 \\
\hline 157 & 90 & 1002.36 & 0.0702 \\
\hline
\end{tabular}

A commercial oil whit this characteristics can be, for example, the Klübersynth GH 6-220 Synthetic Gear Oil.

\section{Results}

Figure 5a shows the pressure field on the symmetry plane. It is possible to appreciate that in the upper cavity the pressure is higher than in the oil bath. That's because this cavity is decreasing his volume. 
The lower cavity, in turn, shows a lower pressure depending on the fact that it is increasing his volume.

Figure $5 \mathrm{~b}$ shows the velocity distribution in the axial direction. It can be appreciate the flux in the axial direction.
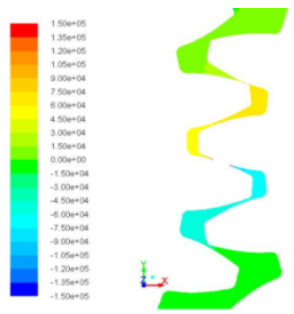

a)

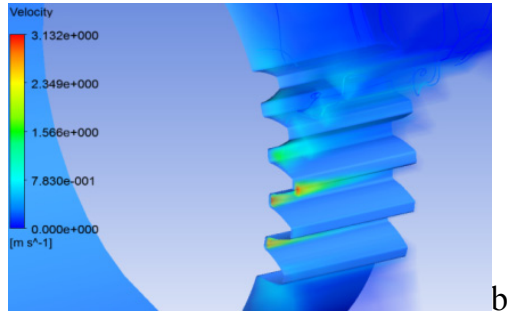

Figure 5: Contour of the pressure $[\mathrm{Pa}]$ on the symmetry plane; b) Velocity distribution in the field of action.

Figure 6 to 8 show the results in terms of power losses on the driving wheel for different operating conditions and for 1 cycle. Since gear mesh is, also the resistant torque necessary to squeeze the oil has a periodic trend.

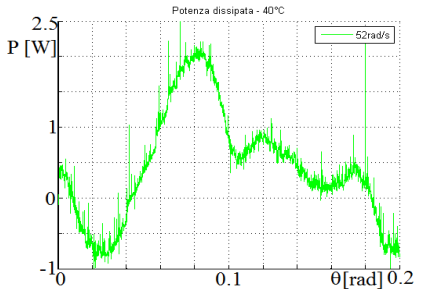

a)
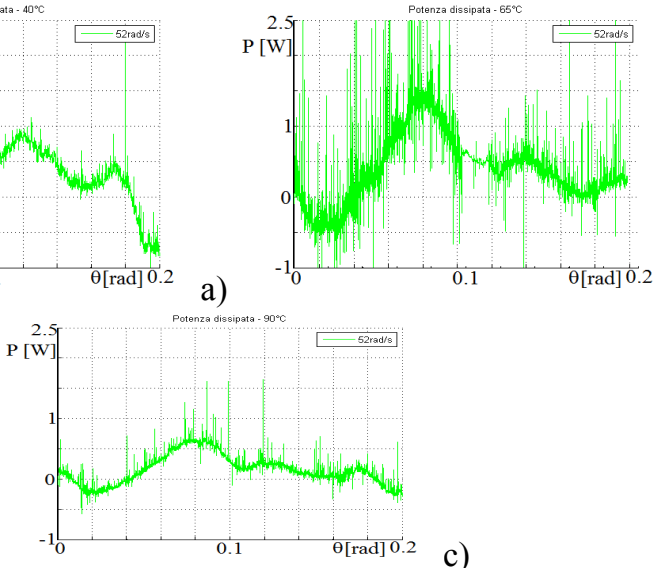

c) b)

Figure 6: Power losses on the driving shaft; a) $40^{\circ} \mathrm{C}-52 \mathrm{rad} / \mathrm{s}$; b) $65^{\circ} \mathrm{C}-52 \mathrm{rad} / \mathrm{s} ;$ c) $90^{\circ} \mathrm{C}-52 \mathrm{rad} / \mathrm{s}$.

From the diagrams it can be seen that, as expected, the resistant torque decreases with temperature while it increases with rotational speed. It can be also seen that this kind of losses are low in the case of the highest temperature and the lower speed (figure 6c), in which they are less than $1 \mathrm{~W}$, while in the case of lowest temperature and higher speed (figure 8a) they became significant. 


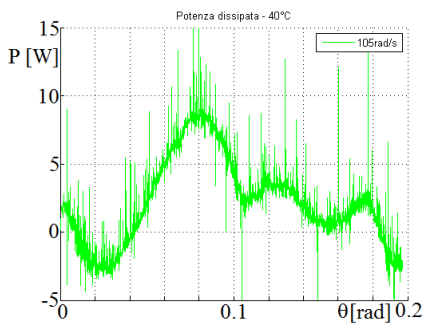

a)

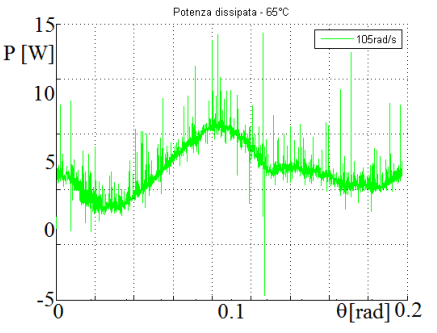

b)

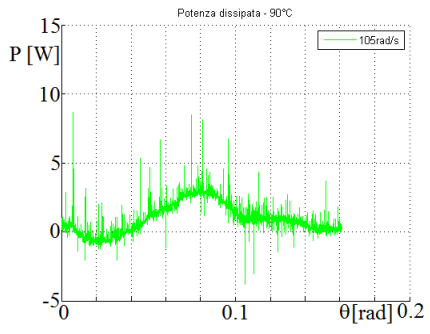

c)

Figure 7: Power losses on the driving shaft; a) $40^{\circ} \mathrm{C}-105 \mathrm{rad} / \mathrm{s}$; b) $65^{\circ} \mathrm{C}-105 \mathrm{rad} / \mathrm{s} ;$ c) $90^{\circ} \mathrm{C}-105 \mathrm{rad} / \mathrm{s}$.

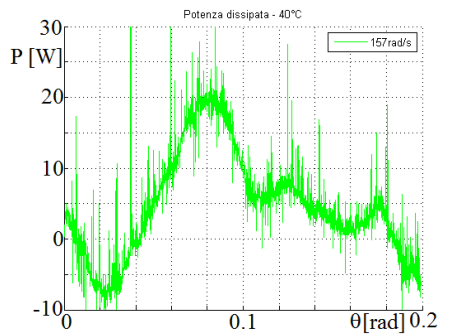

a)
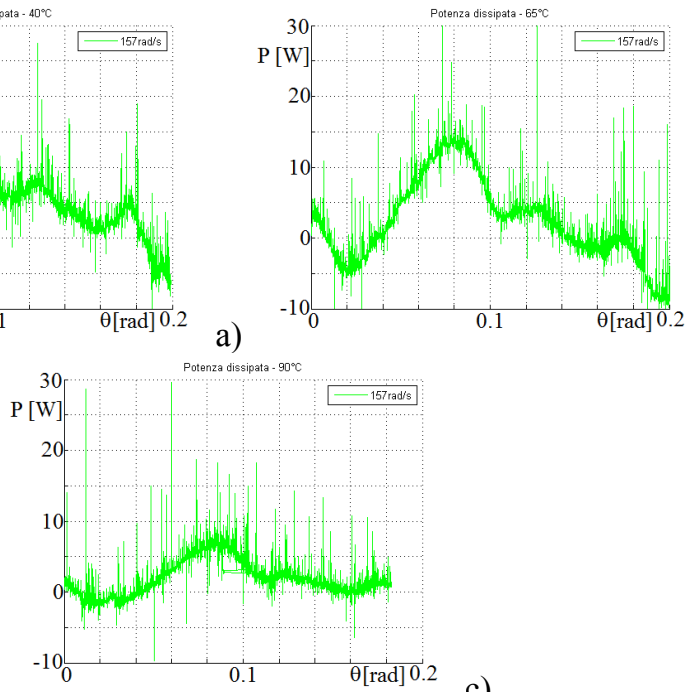

c)

Figure 8: Power losses on the driving shaft; a) $40^{\circ} \mathrm{C}-157 \mathrm{rad} / \mathrm{s}$; b) $65^{\circ} \mathrm{C}-157 \mathrm{rad} / \mathrm{s} ;$ c) $90^{\circ} \mathrm{C}-157 \mathrm{rad} / \mathrm{s}$.

Figure 9 shows the power losses along the contact path. In the position 1 the first teeth pair $(1 s+2 s)$, as shown in figure $10 \mathrm{a}$, is already engaged. The second teeth pair $(2 s+3 s)$ is starting the contact. In the position 2 of figure 8 , the first teeth pair ended the contact (figure 10b). 


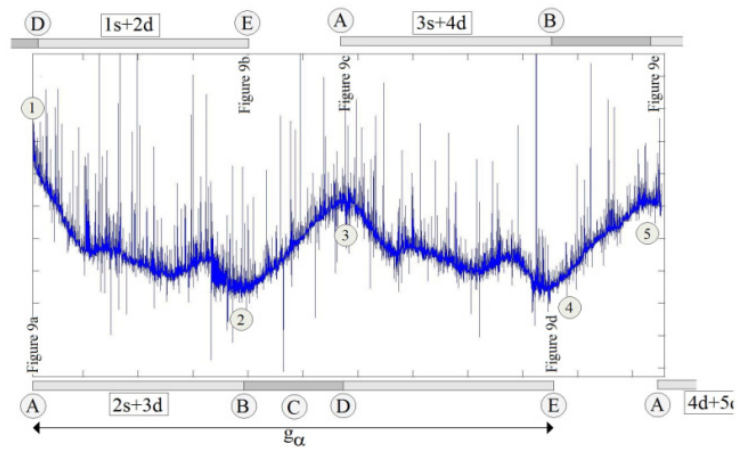

Figure 9: $\quad$ Power losses versus length of contact.

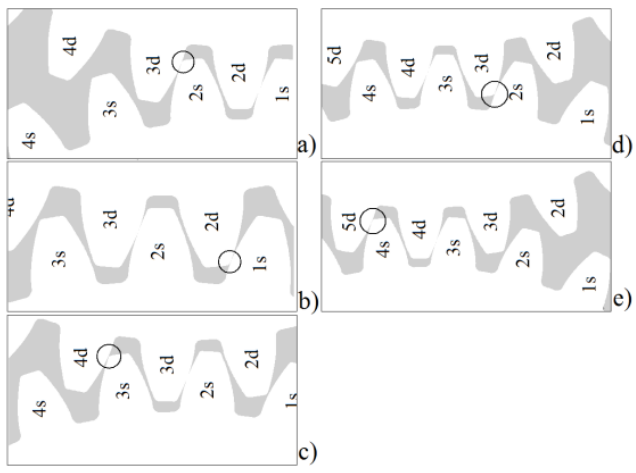

Figure 10: Different engaging steps.

Between 1 and 2, the mating teeth pairs are therefore 2. In the position 3, another teeth pair $(3 \mathrm{~s}+4 \mathrm{~d})$ starts the contact (figure 10c) while the second teeth pair $(2 s+3 s)$ is already engaged. Like in position 2 , in position 4 a teeth pair $(2 s+3 s)$ ended the contact (figure 10d).

From this position to position 5, the engaged teeth pair is again only one, like between position 2 and position 3. Finally, in position 5, like in position 3, a teeth pair starts the contact while another teeth pair is already engaged (figure $10 \mathrm{e})$.

\section{Conclusions}

As reliable models to predict the oil squeezing losses at the gear mating are still not available, a CFD model has been applied in order to predict this important component of losses. The simulations show that this kind of losses increase, as expected, with the rotational speed and decrease with temperature. The results show also that for low regimes and high temperature the kind of losses are particularly low. 
Future works will be the study of other geometries and other kinds of lubrications.

\section{References}

[1] Niemann, G., Winter, H., Maschinenelemente - Band 2: Getriebe allgemein, Zahnradgetriebe - Grundlagen, Stirnradgetriebe - 2.Auflage Springer, Berlin 2003.

[2] ISO/TR 14179-2:2001(E) - Gears - Thermal capacity - Part 2: Thermal load-carrying capacity.

[3] Catalogo generale SKF - Edizione scolastica - Gruppo SKF, Dicembre 2006.

[4] Concli, F., Gorla, C., Arigoni, R., Cognigni, E., Musolesi, M.,:” Planetary Speed Reducers: Efficiency, Backlash, Stiffness", International conference on gears, Munich 2010.

[5] Concli, F., Gorla, C., Arigoni, R., Musolesi, M.:" Riduttori di precisione a gioco ridotto ed alta efficienza", Organi di trasmissione - febbraio 2011, Tecniche Nuove, Milano 2011.

[6] Concli, F., Gorla, C.:"Computational and experimental analysis of the churning power losses in an industrial planetary speed reducers", Multiphase flow IV, Wessex Institute of technology, 2011.

[7] Csobàn, A., Kozma, M., Influence of the Oil Churning, the Bearing and the Tooth Friction Losses on the Efficiency of Planetary Gears, Journal of Mechanichal Engineering 56(2010)4, pp. 231-238.

[8] Concli,F, Gorla,C, Churning power losses in planetary speed reducer: computational-experimental analysis, EngineSOFT International Conference 2012 Conference Proceedings, 2011.

[9] Concli,F, Gorla,C, Influence of lubricant temperature, lubricant level and rotational speed on the churning power losses in an industrial planetary speed reducer: computational and experimental study - International Journal of Computational Methods and Experimental Measurements Wssex Institute of Technology.

[10] D. Strasser, Einfluss des Zahnflanken- und Zahnkopfspieles auf die Leerlaufverlustleistung von Zahnradgetrieben - Dissertation zur Erlangung del Grades Doktor-Ingenieur - Bochum 2005.

[11] Seetharaman, A. Kahraman, Load-Independent Spin Power Losses of a Spur Gear Pair: Model Formulation, Journal of Tribology APRIL 2009, Vol. 131.

[12] Patankar, S.V., Numerical heat transfer and fluid flow, Taylor \& Francis, USA 1980.

[13] Versteeg, H.K., Malalasekera, W., An introduction to computational fluid dynamics - The finite volume method, Longman Group, London 1995.

[14] Comini, G., Fondamenti di termofluidodinamica computazionale, SGEditoriali, Padova 2004. 